\title{
NACIONALIZAR EL SALITRE: DEBATES INICIALES SOBRE EL CONTROL FISCAL DE LA INDUSTRIA (CHILE, 1880-1916)
}

\author{
THE NATIONALIZATION OF SALTPETER: INITIAL DISCUSSIONS \\ ON THE FISCAL CONTROL OF THE INDUSTRY (CHILE, 1880-1916)
}

\author{
Carlos Donoso Rojas ${ }^{1}$
}

\begin{abstract}
El presente artículo analiza las propuestas sugeridas en torno a la necesidad de reforzar la intervención fiscal de la industria salitrera antes del inicio de la Primera Guerra Mundial, atendiendo al carácter estratégico de la actividad para los intereses nacionales, y al sentido etimológico dado en el período de estudio al concepto de nacionalización. Nuestra propuesta remite a un número importante de iniciativas, todas ellas chocaron contra las presiones de los propios industriales, con la nula capacidad operativa del Estado para promover un cambio y, en especial, con los limitados soportes teóricos y funcionales de las mismas propuestas. Desde esta premisa, concluimos que estas condicionantes fueron tanto o más fuertes que la apatía de la clase política por modificar un sistema económico que, patrocinando la libertad comercial, permitió al Estado y a privados disponer de importantes ingresos sin efectuar inversiones relevantes.
\end{abstract}

Palabras claves: salitre, nacionalización, Estado, políticas públicas.

This article analyzes the proposals intended to emphasize the need to strengthen the fiscal intervention in the saltpeter industry before the start of the First World War, in relation to the strategic nature of the activity to the national interests and the etymological sense given in the period of study to the concept of nationalization. Our proposal refers to a number of important initiatives, all of which clashed against the pressures of industrialists themselves, the null operational capacity of the State to promote a change and the limited theoretical and methodological support of such proposals. From this premise, we conclude that these conditions were as strong as, or stronger than, the apathy of the political class to modify an economic system which, by sponsoring the commercial freedom, enabled the State and the private sector to have significant income without making substantial investments.

Key words: Saltpeter, nationalization, State, public policies.

El concepto de nacionalización está asociado al intento del Estado por monopolizar la producción de bienes o la explotación de recursos naturales de carácter estratégico, bajo el control del sector privado y casi siempre de capitales extranjeros. Su objetivo apunta a optimizar el manejo de la economía nacional, o a reestructurarla, poniendo al servicio de los intereses nacionales los recursos y medios básicos en función de las exigencias del interés general (Novoa 1976:24-27).

Los mecanismos de ejecución del proceso son tan diversos como contradictorios en sus resultados. La transformación de la estructura económica del Estado, a partir del control de los sectores productivos claves, lo convierte en un medio de cambio efectivo de las condiciones económicas y sociales, posibilitando una redistribución más equitativa de la renta. Paralelamente, es también un medio de reafirmación de la soberanía contra un poder político o económico hegemónico, marcando de forma simbólica una ruptura o, al menos, una limitación de su dependencia. Casos como el de Uruguay con la nacionalización de la banca, seguros y servicios ferroviarios durante la presidencia de José Battle y Ordoñez (1911-1914), de la industria petrolera en el México de Lázaro Cárdenas en 1938, o de la adquisición en Chile de la Gran Minería del Cobre, apuntan en ese sentido ${ }^{1}$.

Por otro lado, la nacionalización forma parte de procesos modernizadores más complejos, tendientes a instrumentalizar la política económica, reactivando sectores deprimidos, suprimiendo monopolios y canalizando inversiones en áreas prioritarias ${ }^{2}$. La intervención, que supone el fracaso de la iniciativa privada, permitiría estabilizar los ingresos fiscales, como ocurrió en Venezuela con el petróleo en 1976, y como intentó el gobierno peruano en el caso del salitre, entre 1875 y 1879.

Este último es un caso excepcional. En un período en que los intentos por centralizar en el Estado

$\overline{1}$ Departamento de Humanidades, Universidad Andrés Bello, Santiago, Chile. cdonoso@ unab.cl 
la producción y venta de recursos mineros eran improbables, el Perú inició un inédito proceso de intervención fiscal, basado en la necesidad de sanear su economía en crisis por la depreciación del guano, sostén de sus finanzas en las últimas dos décadas. Aunque se ha sostenido en que tanto la creación del estanco salitrero como la posterior adquisición de la industria constituyen el primer intento por establecer un modelo socialista en la historia contemporánea, es evidente que el proceso estuvo lejos de ello. La compra de la propiedad salitrera careció de toda planificación, se realizó mediante la emisión de certificados como medio de pago y su administración se externalizó, primero en un consorcio de bancos y, finalmente, en la Compañía Salitrera del Perú, institución que debió hacer frente a la especulación de dichos documentos y a la insolvencia de la actividad. Como señaló acertadamente Emilio Romero en su Historia Económica del Perú, el gobierno no pretendió establecer una industria ni fomentarla, sino tener en sus manos una riqueza con la cual seguir la dinámica iniciada con el guano, esto es, de contratar empréstitos con su garantía (Romero 1949:409).

En un sentido estricto, la frustrada nacionalización del salitre impulsada por el gobierno peruano no visualizó resolver una disyuntiva esencial, como era crear un modelo que garantizase el equilibrio entre la oferta y la demanda. Si bien al inicio se supuso que la estabilidad de la industria debía ser el resultado de una dinámica económica espontánea, sin mediar la aplicación de medidas coercitivas para su cumplimiento, el factor de eficiencia en los mecanismos de producción y distribución quedó condicionado por las crecientes presiones sociales y fiscales sobre el manejo económico.

Hasta inicios del siglo XX, la idea de insertar al Estado como partícipe activo en la economía mediante la nacionalización de industrias estratégicas implicaba una auténtica revolución, en tiempos en que el crecimiento de los mercados mundiales de bienes y de factores de producción exacerbó el papel de productores, comerciantes e inversionistas en el funcionamiento económico. Los mecanismos de conciliación entre los intereses privados y las necesidades públicas fueron resueltos conjeturalmente en 1908 por el economista italiano Enrico Barone, quien en su estudio Il Ministro della Produzione nello Stato Collettivista, postuló por primera vez los fundamentos teóricos de una economía centralizada. En un modelo de socialismo de mercado como el propuesto por Barone, el Estado poseía medios de producción y una autoridad central determinaba los precios, sin que ello implicase la formación de un monopolio ni restringiese la libertad de gestión de la iniciativa privada. De un modo general, la propuesta de Barone planteaba la posibilidad de coexistencia del Estado como productor y regulador de los medios de producción, con los mecanismos del libre mercado, teniendo como objetivo, en ambos casos, la obtención de beneficios que redituasen la inversión (Barone 1931:132-145).

El modelo de Barone no especificaba si la participación pública surgía de la competencia espontánea o de la aplicación de medidas coercitivas, y no aludía a los mecanismos de apropiación de las instancias productivas por parte del Estado, fuese vía expropiación o confiscación. Tampoco especificaba si la gestión fiscal debía limitarse a potenciar áreas estratégicas o si se trataba de una intervención creciente, proyectable a la estatización de la totalidad de los medios de producción.

Barone fue conocido temprano en Chile, y ya en 1912 fue aludido por el diputado conservador Carlos Subercaseaux, en uno de los debates en torno al futuro de la industria salitrera. Este punto no deja de ser sugerente, pues se trata de una de las escasas referencias teóricas al debate en torno a la nacionalización del salitre, y que seguía la línea crítica planteada por León XIII en Rerum Novarum contra "la fantasía del socialismo". La Encíclica condenaba la lucha de clases y la estatización de los medios de producción, entendiéndolas como alternativas contrarias al emprendimiento individual y la generación de riqueza:

quitado el estímulo al ingenio y a la habilidad de los individuos, necesariamente vendrían a secarse las mismas fuentes de las riquezas, y esa igualdad con que sueñan no sería ciertamente otra cosa que una general situación, por igual miserable y abyecta, de todos los hombres sin excepción alguna (Acción Social de Chile 1932:9).

Hasta fines de la década de 1920, el término nacionalización se utilizó en Chile sólo para definir la incorporación de mayores capitales privados a la actividad, o para aludir a la necesaria participación del Estado en la venta del mineral, pero en ningún caso para avalar un régimen económico centralizado, en donde la actividad se asociara a un monopolio fiscal en la tenencia de los suelos y la producción. 


\section{Propuestas Iniciales}

La riqueza del salitre, difícil de cuantificar en función del tamaño del Estado y del reducido gasto público antes de 1879, implicó una profunda transformación en la estructura financiera y social del país. La Guerra Civil de 1891 y el período de crisis social consecuente fueron, en cierta medida, el reflejo del intempestivo cambio de estatus posterior al control de la región salitrera, que sorprendió a las autoridades políticas sin un plan de acción definido respecto de cómo administrar la actividad y ejecutar los nuevos ingresos ${ }^{3}$.

Con una economía sostenida desde 1878 en un débil patrón de papel inconvertible, y enfrentados a la ausencia de fuentes de entradas sustentables que diversificasen el aporte al erario nacional, la opción de favorecer el libre comercio como eje estructural de la economía fue casi unánime. Ésta se justificó en el principio de la no intervención fiscal y en la decisión de regularizar la cuestión salitrera mediante el canje de parte importante de los certificados salitreros emitidos por el Estado peruano, como una forma de resguardar la libertad de producción y venta.

La decisiva recomendación de la Comisión Consultiva formada en 1880 para definir el futuro régimen salitrero, sugiriendo que "la regla de la buena economía política aconsejaba la abstención de toda intervención gubernativa en los dominios de la industria", no fue sino la más pragmática solución posible para una economía en crisis (Informe de la Comisión... 1880:9). La propuesta de la Comisión se comprende en la lógica económica de su época, sustentada en la aplicación de políticas de efecto inmediato, y no en teorías basadas en supuestos. Entendiéndolo desde una óptica liberal, la función del Estado como orientador del mercado se sostenía en un racionalismo que buscaba, en un mercado desregulado, maximizar ganancias y minimizar sus pérdidas (Hastings 2000:24-26; Hobsbawn 2000:34-35).

En un contexto determinado por el consenso sobre el futuro de la actividad, Francisco de Paula Vicuña planteó una propuesta opuesta a la fórmula planteada por la Comisión Consultiva. Reconocido por ser uno de los más competentes analistas económicos de su tiempo, en 1880 sugirió garantizar la propiedad fiscal de los territorios ocupados procediendo a su inmediata anexión.
En el entendido que la región salitrera debía ser resguardada militarmente, Vicuña aconsejó destinar en ella a seis mil efectivos de ejército, quienes, al mismo tiempo, podrían ocuparse en la explotación de los caliches de las salitreras fiscales, recibiendo por este trabajo una bonificación. Cada cuerpo tendría a su cargo un grupo de oficinas fiscales, dependientes de una Factoría General de Salitres, que operaría en Iquique y que se encargaría de su acopio y venta. De la suma líquida del pago de derechos, el setenta por ciento se depositaría a favor de los tenedores de bonos salitreros y acreedores celebrados por el gobierno peruano, hasta el pago total de lo adeudado (Vicuña 1880:12-15).

Paradojalmente, la necesidad de garantizar la estabilidad productiva en los territorios conquistados puso al gobierno en la disyuntiva de transformarse, al menos temporalmente, en propietario de gran parte de los suelos salitrales en explotación. La ley de abril de 1887, que autorizó pagar los certificados emitidos por el gobierno peruano, transformó al Estado en propietario de 71 de 118 establecimientos salitreros, al comprar casi la totalidad de los vales reconocidos, manteniendo entonces en su poder más de 218 millones de metros cuadrados de suelos en producción (Certificados salitreros... 1887:12).

La propiedad fiscal fue transitoria, pese a la insistencia del senador liberal Adolfo Ibáñez, quien en el debate que aprobó la ley que autorizó el préstamo para cubrir el pago de los certificados pendientes, insistió en la necesidad de aprovechar la coyuntura para implantar un monopolio de producción y venta dirigido por el Estado. Si bien no definió los mecanismos para llevar a cabo el control fiscal, Ibáñez reflexionaba con claridad respecto del futuro del país con la industria:

Abandonar esta posición privilegiada [producir sin competencia] importa a mi juicio renunciar torpemente a los bienes que la naturaleza ha tenido a bien hacernos. Tal vez el monopolio nos costaría algún sacrificio pecuniario; pero este sacrificio, por grande que fuera, nunca tendría las proporciones que el que actualmente se produce con la libre exportación, por más que se le grave con un considerable impuesto fiscal (Cámara de Senadores. Sesión Extraordinaria [CSSE] 32, 7/3/1887:369). 
La visión a futuro de Ibáñez contrastaba con la necesidad del gobierno de convertir los terrenos salitrales en capital productivo en el corto plazo. A esto se sumaba un número importante de juicios iniciados por particulares contra el Estado referidos al reconocimiento de títulos y deslindes, que demandaban recursos y estudios extraordinarios, y las acotadas expectativas del negocio, producto del desconocimiento de la extensión y calidad de los terrenos. Esto definió el carácter transitorio que la actividad tenía para la mayoría de los industriales. $\mathrm{Al}$ respecto, uno de ellos señalaba en 1904 que el objetivo debía ser únicamente la ganancia inmediata al menor costo posible:

Puesto que los yacimientos se agotan en un cierto número de años, cualquier compañía tiene que lograr una tasa suficiente de ganancia, no solamente para obtener una tasa apropiada de interés sobre el capital invertido, sino también para cancelar todas sus obligaciones y devolver a los accionistas el dinero antes que los yacimientos se agoten (Fernández 1981:32).

El gobierno de José Manuel Balmaceda fue el principal impulsor de la reprivatización de la actividad. En un mensaje enviado al Congreso en junio de 1888, el Presidente solicitó autorizar la venta en subasta pública y gradual de los terrenos salitrales de Tarapacá en poder del Estado. La justificación de Balmaceda apuntaba al supuesto perjuicio económico causado por la conservación de las propiedades, "tanto por el gasto que impone el cuidado de ellas i la inactividad de los cuantiosos valores que representan" (Cámara de Senadores. Sesión Ordinaria [CSSO] 4, 13/6/1888:35-36).

La solicitud de remate dio pauta a un intenso debate en la Cámara de Senadores, donde el ministro de Hacienda, Enrique Salvador Sanfuentes, presentó tres opciones para definir el futuro de la industria: avalar la participación del Estado como productor (sea como estanquero o productor monopólico), dar en arriendo los terrenos fiscales, o bien enajenarlos. La posibilidad de transformar al Estado en industrial resultaba para Sanfuentes inconcebible, a la luz de la previa experiencia peruana: "los Estados negociantes i especuladores perturban las nociones del deber de sus hombres públicos, estravían [sic] su conciencia i su criterio, les desmoralizan i desmoralizan al país" (CSSO
20, 25/7/1888:211). La idea de arrendar tampoco resultaba viable, considerando la pérdida de valor de los terrenos producto de la sobreexplotación.

Los argumentos planteados por Sanfuentes apuntaban a la necesidad de vender, en el corto plazo, el mayor número de estacas posibles para atender el servicio del empréstito de $£ 1.113 .786$, contratado para la compra de los certificados salitreros. La tenencia por parte del Estado de establecimientos salitrales, además de costosa, implicaba la inversión de recursos extraordinarios para cercar los terrenos y vigilarlos permanentemente para evitar su explotación ilegal. La necesaria renovación de maquinarias y equipos de producción sumaba un costo adicional, que podía derivar en la paralización indefinida de algunas oficinas (Cámara de Diputados. Sesión Ordinaria [CDSO] 32, 17/8/1888:440-441).

La propuesta fue rechazada sólo por Luis Aldunate, senador del partido Liberal por Tarapacá, quien basó su objeción en que el Estado no podía dejar la marcha de la industria al azar, en virtud de la dependencia de la renta fiscal de la actividad. Bajo el supuesto que la holgura financiera del momento no justificaba la transferencia a privados, Aldunate propuso la intervención activa del Estado en su desarrollo, estimulando el ensanche progresivo de la demanda del salitre, mediante la promoción de los mercados mundiales. Aunque la Combinación Salitrera había iniciado en Europa exitosas campañas de difusión, la conveniencia de la participación fiscal apuntaba a que la retención de terrenos fiscales y el virtual agotamiento de los privados consolidarían, en poco tiempo, un monopolio exitoso.

Si bien Aldunate incluso propuso la creación de una Sociedad Nacional de Explotación de Salitres para la administración del recurso, su iniciativa no fue considerada en el debate del Senado (CSSO 23, 1/8/1888:239). Sin embargo, resulta interesante señalar que la iniciativa del gobierno apuntaba exclusivamente a la enajenación de las oficinas comprometidas por el gobierno peruano. El propio Sanfuentes señaló que las salitreras declaradas en despueble seguirían en poder del Estado, proyectando su eventual explotación futura:

Las conservaremos como fuente inagotable de la futura grandeza de Chile, y como un recurso eficaz para contener las intemperancias de lucro de los especuladores que, consultando tan sólo sus particulares intereses, intenten en cualquier tiempo 
comprometer o detener el vigoroso desarrollo de las rentas nacionales (Bertrand 1910:LVII).

En cierta forma, la anexión de Tarapacá y Antofagasta no logró alterar una dinámica informal, basada en la debilidad de las instituciones fiscales frente a núcleos arraigados. La consolidación de poderes económicos regionales, como señaló un destacado político en 1893, les había permitido constituirse "en verdaderas potencias dentro del Estado" (CSSO 43, 2/9/1920:935; Ibáñez 1893:5-6) ${ }^{4}$. En efecto, el control establecido por la Combinación Salitrera, como los Ferrocarriles Salitreros y el Banco de Tarapacá, de capitales británicos, conformaba un monopolio que restringía la inversión y que amenazaba con expandirse por toda la región salitrera:

No está lejano el día en que Chile no obtenga de tan inmensa riqueza más beneficio que el impuesto a la exportación, i en que la cuantía de los intereses estranjeros acumulados en torno a ella sean una amenaza constante de conflictos i dificultades internacionales (Ibáñez 1893:9).

El temor de que la propiedad salitrera terminase concentrada en manos foráneas generó un intenso debate respecto de la conveniencia de continuar enajenando terrenos fiscales, y a la necesidad de favorecer la participación de chilenos con el objetivo de retener capitales. En agosto de 1892, el diputado liberal José María Díaz propuso nacionalizar la actividad salitrera, creando una "industria exclusiva de Chile" a partir del loteo de terrenos en sitios de trescientas hectáreas, beneficiando a sociedades chilenas con un capital mínimo de 150 mil pesos. Además de vender y promocionar el salitre, el Estado percibiría inicialmente la tercera parte de la producción de cada sociedad, reduciendo su participación a una cuarta parte después de dos años en oficinas organizadas y mantenidas por chilenos. Las cuotas de producción serían visadas por el Estado de acuerdo con estimaciones informadas con un año de antelación (CDSO 27, 13/8/1892:381-382).

Más radical en su propuesta, Luis Aldunate propuso en 1894 restablecer el monopolio creado por el Perú en 1875, expropiando la totalidad de establecimientos y fijando contratos de elaboración entre el gobierno y los industriales salitreros. De este modo se garantizaban cuotas de producción y se estabilizaba el precio, estimulando, de paso, la llegada de inversionistas o sociedades chilenas, quienes tendrían derecho exclusivo de arriendo de las oficinas en producción (Aldunate 1894:81-83).

Aunque ambas iniciativas no fueron consideradas para su debate parlamentario, la voluntad política de aumentar la participación de inversionistas nacionales en la industria se reflejó en el remate de 1894, en donde, como una forma de estimular esa tendencia a futuro, el gobierno presentó al Congreso un proyecto de ley que otorgaba a inversionistas chilenos facilidades de pago en posteriores remates, pudiendo costear la compra de terrenos en plazos preferenciales frente a los capitales extranjeros (Cámara de Diputados. Sesión Extraordinaria [CDSE] 17, 23/11/1893:273; CDSE 21, 24/10/1895:50).

La proyectada participación de inversionistas nacionales se vería condicionada por factores vinculados al propio dinamismo de la actividad extractiva. El incremento de la producción, de 20.612.742 quintales en 1893 a 26.926.186 en 1895, derivó en la sobreoferta y en el descenso de su valor. Paralelamente la depreciación de la moneda, como consecuencia de la conversión monetaria de 1895, redujo los márgenes de utilidades y aumentó la deuda de pequeños y medianos industriales, quienes comprometieron compras de terrenos en libras esterlinas o letras de cambio. De acuerdo con la estimación de un salitrero en 1897, las inversiones realizadas tres años antes se habían devaluado en más de un treinta por ciento (Millar 1994:248-264; Vergara 1894:76).

Es indudable que la causa de la crisis del período respondió más al efecto de la sobreproducción que a una caída notoria del tipo de cambio, aunque también pudo incidir el hecho que los gastos de explotación, de fletes y el pago de los derechos de exportación fueron altos, tanto como para limitar la rentabilidad incluso cuando la calidad del caliche fuese alta y la demanda sostenida (Hernández 1930:143-144). De cualquier modo, la participación de capitales chilenos se inhibió, incluso cuando el retraso en los compromisos de pago fue solucionado con la reprogramación de las deudas. En 1895 , poco más del doce por ciento de la propiedad salitrera estaba en manos de connacionales (CDSE 36, 20/1/1896:419-420; Diario Oficial 24/2/1897; Hernández 1930:146). 


\section{La Idea de Nacionalizar}

El uso del concepto de nacionalización a fines del siglo XIX responde a variables diametralmente opuestas al caso peruano. Mientras la política fiscal emprendida en 1875 apuntaba a sanear una economía en quiebra, para el caso chileno el término aludía a la necesidad de retener las utilidades en el país, sin que ello exigiera la intervención estatal como operador de la industria, ni siquiera como regulador de la actividad. En ese sentido, la idea de nacionalizar el salitre se configuró en torno a la necesidad de limitar o condicionar la presencia de capitales extranjeros, pero en ningún caso en función de un análisis de cuánto y cómo producir, ni menos quién debía hacerlo. La propuesta de nacionalizar tampoco incluía a pequeños y medianos productores, no distinguía entre el origen y destino de las inversiones, nada refería sobre los beneficios residuales de favorecer la participación de chilenos y las necesarias mejoras en la condición socioeconómica de los trabajadores de la industria, ni tampoco visualizaba políticas de reinversión del capital.

Sin un corpus de ideas que la sustentasen, los discursos nacionalistas del período fueron el resultado de la irresoluta definición fiscal en políticas económicas. Gellner (1994:144-146) identifica este ciclo como el período más violento e ideológicamente irresoluto de las repúblicas en formación, creando una situación social inestable, marcada por las desigualdades económicas y educativas. En efecto, el modelo modernizador chileno asociado al nacionalismo, ligado en el siglo XIX a conceptos como progreso, ferrocarril y ciencia, aparece en el nuevo siglo renovado en torno a los de industria, industrialización y desarrollo, sin especificar los mecanismos de transición entre una etapa y otra, y sin siquiera haber consolidado la primera.

Esta nueva estructura asignaba al Estado un rol creciente en la gestión económica, aunque también evidenció la escasa preparación teórica y práctica de sus promotores para fundamentar sistémicamente su inclusión. En octubre de 1902, Darío Sánchez, diputado liberal-democrático, presentó en la Cámara un proyecto que contemplaba la asignación exclusiva de privilegios de explotación salitrera a inversionistas chilenos. Sánchez buscaba fomentar la riqueza nacional contra lo que definía como "la ola amenazante del monopolio extranjero en la factoría chilena de Tarapacá, tan deprimente para la riqueza, para la moralidad para el trabajo i para el buen sentido chileno" (CDSE 3, 24/10/1902:48-50).

La iniciativa exigía, como elemento esencial para iniciar el proceso de nacionalización de la actividad (como lo denominó), la derogación de las leyes hasta entonces vigentes para la venta o remate fiscal de los terrenos salitrales, lo que implicaba su retorno a manos del Estado, aunque nada refería sobre indemnizaciones o compensaciones por expropiación. En poder de la Delegación Fiscal de Salitreras, ésta los entregaría en concesión a ciudadanos y sociedades exclusivamente chilenas, con solvencia necesaria para invertir en la actividad y por un plazo máximo de quince años. El Estado retendría quince o veinte centavos por cada quintal elaborado, dependiendo de la ley media del caliche, sin perjuicio de seguir pagando el derecho de exportación correspondiente.

Sánchez se basaba en estimaciones derivadas del alto precio que, por entonces, alcanzaba el salitre en los mercados internacionales, y no contemplaba limitaciones a la producción, partiendo de la presunción que el precio del salitre se mantendría estable e invariable, más allá de la cantidad a producir y de la irregular demanda.

Meses después, el diputado radical Perfecto Lorca presentó un nuevo proyecto en la misma línea de su predecesor, insistiendo en la prohibición de enajenar depósitos salitrales, esta vez por un lapso de quince años. La moción incluía un plazo de noventa días para que los concesionarios o adquirientes de pertenencias salitreras otorgadas al sur de Tarapacá iniciasen demandas contra el Estado, a fin de obtener la mensura de sus pertenencias (CDSO 18, 24/6/1903:385).

Lorca, a diferencia de Sánchez, apuntaba a regularizar la propiedad salitrera evitando reivindicaciones bolivianas en Antofagasta, en un período en que la presencia chilena en la región era sólo administrativa. A inicios de siglo se habían entablado algunos juicios de connotación pública contra el Estado, solicitando la mensura de pertenencias salitreras ubicadas en Tocopilla, aduciendo haber sido concedidas por autoridades bolivianas antes de 1879. Pese a que el Consejo de Defensa Fiscal logró demostrar, en algunos casos, que las solicitudes se apoyaban en autorizaciones parciales, se temió que el reconocimiento de algunos títulos pudiese sentar precedentes a futuras reclamaciones. La exitosa negociación alcanzada por la Compañía Salitrera del Perú tras demandar al Estado chileno en 1886 por despojo de la propiedad fiscal peruana del 
salitre, y el acuerdo ad referendum alcanzado con el gobierno chileno en 1903, fue visto como una amenaza que contribuyó a exacerbar el particular nacionalismo económico del período (CDSO 53, 31/8/1903:1.031-1.032; Memoria del Delegado Fiscal... 1903:95-98).

La visión de un Estado subsidiario iba paralela al rol de garante de la producción nacional, otorgando avances que posibilitaban la continuidad operativa de industrias en crisis, o emitiendo bonos necesarios para desarrollar en Chile actividades industriales prioritarias. Desde inicios de siglo, el porvenir de la industria del carbón, del hierro, del acero, del cobre y del salitre se ligó indisolublemente a un Estado convertido en un instrumento para posibilitar el progreso industrial privado (Ávalos 1905; González 1915; Sundt 1907).

Ligado a este punto, un par de ejemplos pueden señalarse como distintivos de la original conceptualización nacionalista del período. Como una fórmula de romper el control absoluto establecido en la industria por la Combinación Salitrera, Francisco Olivián sugirió, en 1893, vender oficinas salitreras o terrenos sólo a personas o sociedades chilenas, fijando condiciones que impidiesen la transferencia a extranjeros. La obligación de los nuevos productores chilenos sería cumplir regularmente el pago de las propiedades al Estado, a través de un porcentaje por quintal producido, y cumplir una cuota anual de producción, prohibiéndoles formar parte en la Combinación:

Ayudar, dar facilidad al capital y trabajo chilenos, para que la nacionalización de la industria salitrera sea un hecho, sin ser absoluta, es simple y sencillamente formar auxiliares que a su vez ayudarán al Gobierno a resolver un problema de presente y porvenir y dar cima a una obra de patriotismo que se impone con urjencia, para salvar de un mal grave que se viene encima (Oliván 1893:6-8).

En la misma línea argumentativa, en 1908 el cronista Nicolás Palacios planteó algunas medidas de estímulo a la industria salitrera basadas en la concreción de inversiones nacionales, sin que ello afectase la propiedad privada ni los capitales extranjeros comprometidos. Entre ellas estaban la supresión o rebaja del impuesto a la exportación de salitre a los nuevos productores, y la entrega por parte del Estado de subsidios directos mediante préstamos en dinero. En retribución, la industria debía emplear mano de obra exclusivamente nacional, tanto para las faenas mineras como para la administración técnica de la producción:

Es deber de alta previsión patriótica que pesa sobre los chilenos el de dejarse para sí siquiera los últimos años de vida de esta industria. Cuando llegue el caso de tener que rebajar los derechos de esportación... el sacrificio que esa medida imponga al Erario Nacional sea en bien de los chilenos, $\mathrm{y}$ cuando sea forzoso suprimirlos del todo, que Chile obtenga siquiera como beneficio las ganancias que pueden procurarse alguno de sus hijos (El Chileno [Valparaíso]: 23/4/1908; Bermúdez 1968:199-249).

Por su parte, los lineamientos doctrinarios de los principales partidos políticos del período, sin explicitarlo, respaldaban la libertad del modelo económico, enfatizando una perspectiva más pragmática que ideológica. El Partido Conservador, con un discurso antisocialista definido por su nexo con la Iglesia, consideraba un desequilibrio moral la imposición del "Dios Estado" sobre la iniciativa individual. El Liberal Democrático, por su parte, declaraba su propósito de amparar las industrias nacionales existentes y fomentar el establecimiento de otras nuevas a partir del emprendimiento privado. Desde otra perspectiva, el Partido Liberal proponía estimular el desarrollo posible de la industria agrícola y minera, procurando que estas fuentes de riqueza se mantuviesen en manos nacionales (La Convención Conservadora... 1895: 9; Convención del Partido Liberal Democrático... 1908:47; Convención del Partido Liberal 1907:355).

El Partido Obrero Socialista, al cual adhería parte importante de los núcleos obreros en la región salitrera, focalizó su atención en las condiciones laborales de los trabajadores y en la posibilidad de aumentar su participación en la toma de decisiones en materias referidas a la industria. El programa fundacional del Partido aspiraba a crear una Cámara del Trabajo, donde tuviesen representación los trabajadores para estudiar las necesidades de la industria y de los productores, encargándose además de resolver los conflictos entre capital y trabajo, sin aludir al rol del Estado en el manejo económico. Más original era la posición del Partido Nacionalista, 
entidad que definía nacionalización de la industria simplemente como "el hecho de pertenecer ellas a chilenos o extranjeros radicados en el país, de manera que sus utilidades no sean extraídas para ser invertidas en el extranjero" (Recabarren 1915:6; Subercaseaux 1918:23).

Sin una estructura ideológica definida en torno a cómo proceder con una actividad primordial para el interés nacional, la solicitud de una mayor injerencia del Estado en la industria salitrera, fuese como fiscalizador o como regulador de ella, careció de la sistematización necesaria, lo que explica la diversidad de propuestas en torno a reformar el statu quo de la actividad y el escaso consenso creado en torno a ellas.

\section{La Inserción del Estado}

Como un tema transversal a todo el ciclo salitrero, la estabilidad en la demanda por salitre a inicios del siglo XX se vincularía de modo indisoluble al debate en torno a la propiedad e influencia de los capitales extranjeros en la industria. Como se indica en la Tabla 1, en 1884, el 36 por ciento de las oficinas operativas en el Norte Grande estaba bajo control de chilenos. En 1901, el porcentaje se había reducido al quince por ciento, teniendo once años después participación en menos de un cuarenta por ciento del capital invertido y de un tercio del porcentaje del mineral exportado (Antecedentes sobre la industria salitrera... 1925:8-9; Hernández 1930:160).

Tabla 1. Producción del salitre según nacionalidad del capital (en porcentajes).

Production of nitrate by nationality of capital (in percentages).

\begin{tabular}{cccccc}
\hline & 1878 & 1884 & 1895 & 1901 & 1912 \\
\hline Peruano & 58 & & & & \\
Inglés & 13,5 & 20 & 60 & 55 & 38,5 \\
Anglo-chileno & & 14 & & & \\
Chileno & 19 & 36 & 13 & 14 & 37 \\
Alemán & 8 & 17 & 8 & 15 & 15 \\
Otros & 1,5 & 13 & 19 & 16 & 9,5 \\
\hline
\end{tabular}

Fuente: Sunkel (1982:136).

El problema, como lo señalaba Bertrand (1918:23-27), pasaba por la concentración de buena parte de la industria en la Combinación Salitrera, organización formada en 1884 por las grandes productoras, con el objetivo de mantener al alza el precio del nitrato, regulando la producción. La fórmula excluía a pequeños productores, quienes no podían afrontar de modo competitivo las condiciones de venta a futuro impuestas por la Combinación, y también perjudicaba los intereses del Estado, considerando que el gasto público dependía de la cuantía del salitre exportado. La vulnerabilidad fiscal se evidenciaba al no disponer de medios para regular la exportación, aun cuando las señales del mercado recomendaban conciliar el beneficio privado y la dependencia fiscal sin alterar el libre intercambio, lo que se lograba con un precio regulado por los oferentes (González 2011:419-428).

En 1901, una propuesta de los diputados liberales Maximiliano Espinoza y Gonzalo Bulnes buscó contrarrestar el monopolio de la propiedad salitrera y crear condiciones para insertar al Estado en la industria. Esto se lograría facilitando la explotación de terrenos en manos de chilenos mediante la cesión de créditos por parte de una Caja de Crédito Salitrero, a crearse para tal efecto (CDSE 9, 6/11/1901:202-203). Algún tiempo después, el demócrata Alfredo Yrarrázabal propuso otra fórmula de control indirecto sobre la industria, al sugerir el cobro de derechos aduaneros diferenciados y porcentualmente crecientes sobre el salitre cuando se exportase a niveles superiores al consumo (CDSE 26, 14/12/1905:682-683).

La moción no fue discutida por el veto de un grupo de parlamentarios, pero dio relevancia a un tema poco abordado, como era la relación existente entre personeros públicos y la industria salitrera. $\mathrm{La}$ acusación del conservador Gonzalo Echeñique, quien denunció la colusión de intereses parlamentarios, individualizando a "los partidarios del monopolio salitrero y usufructuarios de la industria" (CDSE 40, 2/1/1906:1.014), creó expectativas impensadas ante un tema hasta entonces relegado del interés público, y que se expresó en notas editoriales en medios de prensa de influencia. Mientras El Diario Ilustrado sugería en noviembre de 1906 la creación de una Dirección Fiscal del Salitre que, entre otras funciones, velaría por transparentar posibles conflictos de intereses de personeros públicos, en septiembre de 1908 un editorial de El Mercurio señalaba que, conocido el vínculo de la industria con la clase política, era necesario impulsar una política especial hacia el nitrato, advirtiendo que "el Estado está tan ligado a la industria que debe tomar parte en la alta dirección de ella" (Citado en Ortiz Letelier 2005:39).

La inclusión de Alejandro Bertrand marca un punto de inflexión en el debate, al proponer una 
visión técnica a un tema que se había politizado, transformándose, con el correr de los años, en referencia obligada en toda discusión en torno al futuro del salitre. Ya en 1892, siendo Delegado Fiscal de las Salitreras, propuso la urgencia de intervenir en la organización de la industria como un deber de Estado, por ser propietario de las reservas, regulador potencial de la producción por concesiones o remates, y del precio, por el impuesto de exportación (Bertrand 1892:16-19). Años después, mientras ejercía como Delegado Fiscal de Propaganda Salitrera, Bertrand publicó en París La crisis salitrera, obra en la que presentó el primer programa de política salitrera sobre bases analíticas, asignando al Estado una participación preponderante, basada en ocho puntos:

1. Exploración completa de la zona salitrera en extensión, profundidad y riqueza.

2. Estudio del mejor agrupamiento de los depósitos y división administrativa correspondiente, para mejorar la eficiencia en explotación y transporte del salitre.

3. Constitución definitiva de la propiedad salitrera.

4. Ejecución total o parcial del Estado de estudios y trabajos de interés general para la industria salitrera, desde la exploración de capas acuíferas, apertura y conservación de caminos públicos, construcción y funcionamiento de ferrocarriles, hasta las obras de puerto para facilitar el embarque y carguío del salitre.

5. Fomento en los procedimientos de extracción, elaboración y transporte tendientes a disminuir el costo de producción, instalación de un laboratorio de experimentación y asignación de premios sustanciales a inventores de mejoras efectivas en la elaboración.

6. Apoyo administrativo y económico del Estado a todo consorcio de productores. Este debía orientarse a regularizar las condiciones de producción y exportación, y a regular el precio de venta del salitre en el mercado mundial, con el objetivo de simplificar los mecanismos del intercambio entre productores y demandantes.

7. Estudio de la posibilidad de ejercer un control económico efectivo sobre el precio máximo del salitre en puertos europeos. Esto podía ser posible reemplazando el derecho fijo de exportación por otro graduado mensual o trimestralmente, con arreglo a una escala que impidiera a los productores elevar artificialmente los precios en perjuicio del consumo.
8. Fomento del consumo, auxiliando a la propaganda técnica e industrial (Bertrand 1910:83-84). Aunque existía plena conciencia que la estabilidad de la actividad dependía de la acción coordinada con los industriales, la dificultad siempre fue el cómo hacerlo. A juicio de un contemporáneo, el problema del control de la producción se reducía a un dilema simple, pero insalvable para la estructura de la industria: si se fijaba una cantidad suficiente para cualquier aumento eventual de la demanda, el mercado se alarmaba y se deprimían los precios. Por el contrario, si se fijaba una cantidad moderada, se corría el riesgo de detener el aumento de consumo por falta de existencias disponibles (Mena 1916:12-14).

El tema no era menor, considerando que el financiamiento del Estado dependía directamente de la industria. A fines de 1909, en plena bonanza exportadora, el diputado conservador Darío Urzúa advertía sobre los riesgos de no contemplar los riesgos de la competencia:

seguimos gastando como ricos opulentos por una parte, considerando perdurables e inextinguibles las rentas del salitre, $i$ hemos visto, por otra, que mientras los industriales i capitalistas del mundo entero siguen invirtiendo sumas colosales i continúan poniendo a prueba a la ciencia para derrotarnos, nosotros, con la más grande i censurable imprevisión, hemos continuado en nuestra orjía de gastos fiscales i no hemos hecho nada por armar a nuestra industria salitrera de medios de defensa (CSSO 66, 29/11/1909:1.485-1.486).

La falta de previsión denunciada por Urzúa se dio en un contexto de incertidumbre creado tras el anuncio del término definitivo de la Combinación Salitrera. Esta situación no dejaba de ser contradictoria, pues aunque en el papel eliminaba un trust que restringía la libertad de producción y venta, también dejaba en evidencia el equilibrio precario existente entre la capacidad operativa de la industria y los requerimientos de un mercado altamente competitivo.

El incierto panorama de la actividad frente a su nuevo estatus hizo surgir las primeras voces pidiendo "una sabia y prudente intervención del Estado". En marzo de 1909, el gobierno designó una Comisión Consultiva para crear y promover 
iniciativas respecto de la producción, elaboración y ventas y mecanismos de regularización de la propiedad salitrera.

La Comisión presentaría cuatro observaciones generales respecto de la participación del Estado en la actividad, transformándose en el primer manifiesto de intenciones fiscales sobre la industria. A juicio de la Comisión, el Estado debía promover el estudio de nuevos métodos de producción, por medio de subsidios, e impulsar la organización de un gremio de industriales con el fin de centralizar las ventas. Paralelamente, aportaría con la regularización definitiva de la propiedad salitrera y, en particular, con la institucionalización de la industria en torno al Consejo Directivo del Salitre, coordinando los intereses fiscales con los privados (Circular Trimestral de la Asociación de Productores de Salitre [CT] 47, 1909:10; CDSO 74, 7/8/1909:1.727).

En noviembre de ese año, la Comisión fue formalizada en el Consejo Salitrero, organismo creado para "señalar los rumbos e indicar las soluciones de una buena política salitrera". Durante su vigencia, hasta 1914, el Consejo cumplió tácitamente las funciones del sugerido Consejo Directivo del Salitre, velando por la tuición de los derechos fiscales y por la correcta constitución de la propiedad salitrera, aunque limitado a un carácter meramente propositivo y sin mayor conexión con la Asociación Chilena de Propaganda. Esta impugnó la ausencia de representantes de los productores en la Comisión inicial, optando por potenciar una agenda propia, organizando una fallida Asociación de Industriales Salitreros, e impulsando la creación de un Instituto de Técnicos del Salitre (CT 61 1913:140-141).

El impasse fue solucionado con la inclusión de representantes de los productores en el Consejo Salitrero, posibilitando la inédita elaboración de un programa salitrero conjunto. Presentado en 1913, la propuesta señaló la necesidad de fijar los lineamientos permanentes que permitirían al Estado mantener los ingresos por el mayor tiempo posible, garantizando la permanencia de actividad mediante inversiones en áreas estratégicas. Estas debían basarse en la ejecución de cuatro puntos fundamentales: fomento de mejoras en la explotación y elaboración del mineral, para obtener el máximo rendimiento al menor costo posible; reforzamiento a nivel mundial de la propaganda, lo que implicaba el aumento de las subvenciones; abaratamiento de los costos de traslado desde las oficinas hasta los puertos costeros, y eliminación de intermediarios (CDSO 17, 30/6/1913:423-427).

Las propuestas del Consejo Salitrero tuvieron buena acogida en el gobierno, en medio de un ambiente determinado por el optimismo respecto del futuro de la industria. La gran huelga de obreros del carbón de 1912 en Inglaterra, que paralizó los envíos del mineral a Chile, fue percibida como una señal de la fuerza de la actividad respecto de los abonos sintéticos, pues al afectar al tráfico naviero, generó incertidumbre respecto del futuro de los envíos a Europa, favoreciendo la especulación (Bertrand 1912:43).

Pese a las evidencias que avizoraban un conflicto mayor en Europa que involucraría a los principales mercados compradores del salitre, el inicio de la guerra en Europa impactó en Chile de un modo inesperado, sin que ninguno de los actores involucrados hubiese tomado resguardos para hacer frente a la contingencia. El cierre de los mercados salitreros, en especial del alemán (básicamente por las restricciones impuestas al tráfico marítimo), sorprendió al país con un significativo stock del mineral en los puertos. En junio de 1915 se estimaba que el saldo de salitre disponible sólo en Iquique, descontando las estimaciones de producción y exportación, era de 1.043.000 quintales. Esto obligó a detener la producción y cerrar 35 oficinas (Esportación de salitre... 1915:5-7).

El conflicto confirmó que la industria chilena no estaba preparada para enfrentar la competencia de abonos artificiales anunciada desde inicios de siglo. En 1907, Belisario Díaz Ossa, ingeniero y profesor de la Cátedra del Salitre de la Universidad de Chile, presagiaba que el futuro del salitre dependería de cuan preparado estuviera el país para afrontar la arremetida de los fertilizantes sintéticos. Mientras en Europa la producción de abonos en diez años había duplicado su rendimiento con relación a su costo de producción, en Chile los depósitos de caliche se seguían cateando rudimentariamente. La solución, a juicio de Díaz, pasaba por invertir en tecnología, formar personal preparado en las técnicas apropiadas y mejorar las condiciones de vida de los trabajadores. Paralelamente, debían optimizarse los mecanismos de transporte del mineral, y reducir el número de intermediarios existentes entre el productor y el consumidor (Díaz Ossa 1907:6-8).

Desde la publicación del estudio de Díaz Ossa, hasta el inicio del conflicto, la industria no experimentó inversiones relevantes, y la importancia 
de las sustancias sintéticas fue relativizada por los propios productores, pese a la insistencia de los expertos en la materia. La subvaloración de la competencia descansaba en argumentos reales, pero prescindibles, como la mayor eficacia del nitrato, su menor costo, los riesgos en la manipulación de sintéticos, su limitada capacidad de producción y lo acotado de sus mercados. Incluso en tiempos de contracción de las exportaciones, el análisis no consideraba la posibilidad del cierre de mercados, las aristas políticas relacionadas con la aplicación de medidas proteccionistas, o las progresivas mejoras introducidas a la fabricación de los abonos.

\section{Conclusiones}

La Gran Guerra europea sorprendió a la industria salitrera con una estructura similar a la existente antes de la ocupación chilena, en donde los mecanismos de producción, las relaciones entre obreros y empleadores, la ausencia de competencia y la anulación de iniciativas opcionales al marco operativo vigente determinaban la configuración de la actividad. En un marco con éste, los proyectos en torno a centralizar las ventas del salitre debieron orientarse a resolver los conflictos que derivarían de un cambio mayor que alteraba el orden establecido, e integraba al Estado como un actor relevante de la industria. Con toda sensatez, en 1916 un anónimo se preguntaba cómo controlar la producción y cómo determinar la participación del Estado y, en lo fundamental, si la organización debía ser espontánea u obligatoria, considerando que, entre otros factores, los costos de producción eran diferentes entre una salitrera y otra (El Mercurio [Santiago]:1/9/1914; Salitrero 1916:30-33).

A partir de 1915, el debate en torno al futuro del salitre involucró necesariamente la participación fiscal, tanto porque resultaba prioritario mantener la continuidad de la industria, como porque sólo el Estado parecía garantizar su estabilidad frente al incierto devenir. Hasta el término del conflicto, las propuestas de centralización o consignación del salitre fueron una constante que derivó, incluso hasta mediados de los años veinte, en propuestas de gobierno para organizar compulsivamente a los productores, e incluso expropiar la industria.

La progresiva decadencia de la industria salitrera respondió a factores externos de difícil control local, pero también a la incapacidad de inversores y comerciantes de prever condiciones que les permitieran aspirar a tener una posición predominante en los mercados. Esto posibilitó el verse impedidos de competir contra una industria, como la de los abonos artificiales, que producía con altos rangos de eficiencia, satisfaciendo plenamente la demanda interna y conciliando estándares de calidad con precios competitivos.

Los industriales, por el contrario, optaron por justificar la crisis en los crecientes costos de producción en las oficinas salitreras y, principalmente, en la alta tributación a la que era sometida la actividad. A juicio de Jorge Jones, representante de los industriales, las leyes sociales promulgadas hasta 1916 (contrato de trabajo, seguro obligatorio, accidentes de trabajo, sindicatos industriales y empleados particulares) habían dañado a la industria, al implicar un recargo efectivo equivalente a un aumento de dos pesos por quintal métrico, eso es, cincuenta millones de pesos anuales.

El futuro del salitre, según Jones, dependía del aporte fiscal para la modernización de su infraestructura, la supresión de nuevos impuestos y la rebaja de los vigentes, pero no de su integración como regulador de la producción ni como agente colocador. A su juicio, la intervención del Estado era una medida compulsiva y contraria a los principios liberales de la legislación chilena. Aunque la solución al problema salitrero pasaba por el control de la producción y la homologación de los precios de venta, ésta debía ser coordinada a través de una Asociación de Productores, sin participación fiscal, cuyo rol debía limitarse al de recaudador de contribuciones:

Tengo la íntima persuasión de que la industria se organizará a sí misma, con la buena voluntad y con la protección del gobierno; pero sin medidas compulsivas a que no necesita acudir y que seguramente encontrarían resistencia en un Congreso en que figuran muchos hombres partidarios del libre desarrollo del comercio y de la industria (El Mercurio [Valparaíso]:16/12/1917).

La opinión de Jones se apoyaba en la premisa simple de que el mercado podía y debía autorregularse, aunque no visualizaba hasta qué punto la imprevisión de los productores podía alterar dicha lógica.

Una segunda arista de análisis apunta al grado de responsabilidad que pudo competer al Estado en la crisis salitrera. A fines de los años veinte, la Asociación 
de Productores insistía en señalar que la contracción de las exportaciones fue el resultado de la falta de voluntad política de la clase dirigente para instaurar un modelo de protección eficaz hacia el salitre. Esto, en el entendido que ésta debió orientarse a liberar del pago de derechos aduaneros a los insumos básicos de la actividad y, por supuesto, a un cambio del modelo tributario a otro que ajustase el pago de impuestos a las utilidades percibidas o que impusiese un derecho flexible, dependiente de los precios de venta (Acta de la Junta General... 1928:12).

Aunque el Estado mantuvo una posición distante frente al desarrollo de la actividad, evitando la intervención directa en la producción y venta, la industria obtuvo consideraciones excepcionales para su operación. Estos se centraron en el uso de recursos del Fondo de Conversión para comprar bonos salitreros en 1907, y la Ley de Auxilio Salitrero, promulgada en 1914, con vigencia de tres años, y renovada hasta 1923, destinadas a anticipar el pago de parte significativa de la producción con la emisión de letras con garantía fiscal, con la condición de mantener las principales oficinas operativas.

El Estado creó también una completa estructura de apoyo a la industria. La formación en 1909 del Consejo Salitrero complementó la función del ministerio de Hacienda en materias tributarias, actuando como organismo consultivo para orientar y definir políticas públicas vinculadas a la industria. Paralelo a ello, se fomentó una institucionalidad financiera a partir del Estado que trató de reforzar la industria mediante la centralización de operaciones crediticias, a través del frustrado Banco Salitrero del Estado, impulsado durante el gobierno de Germán Riesco en 1902, y la Caja de Crédito Salitrero inaugurada en 1908 y en funciones hasta 1911, paralelo a las funciones del sistema bancario. La liquidación de los bancos Mobiliario (1907) e Hipotecario Salitrero de Chile (1908) y de la propia Caja de Crédito Salitrero (1912) tuvieron como responsables a los grandes conglomerados salitreros, quienes incumplieron los compromisos asumidos sin que los gobiernos de la época interviniesen, siquiera para dar una señal de estabilidad a un sistema financiero expuesto y cuestionado por su falta de liquidez.

Es probable que "el maridaje política-negocios" demostrado por Gonzalo Vial justificase el resguardo, considerando que políticos de primera línea (mandatarios inclusive) tuvieron en el proceso una participación transversal, como accionistas, liquidadores, socios capitalistas, aunque también, ocasionalmente, como damnificados del sistema (Vial 1996 II:603-605).

Si bien el nexo entre los intereses económicos del salitre con los círculos del poder político es asumido por la historiografía nacional (marxista y conservadora) como uno de los elementos constitutivos de la relación de la industria con el Estado, no queda del todo claro porqué se insistió en preservar un modelo económico que, desde inicios de la ocupación del Norte Grande, demostró ser altamente riesgoso con relación a los formidables capitales invertidos. Pese a ser un monopolio natural de demanda creciente, la estructura de la industria jamás pudo regular el precio de acuerdo con los volúmenes producidos, precisamente por el afán de defender la libertad de los productores, y en la idea que el mercado se autorregulase. Esto no deja de ser una paradoja considerando que, una vez masificados los abonos artificiales, el tema fue cómo no abatir el precio aumentando la producción, sin tampoco tentar a la reacción de la competencia.

Obviando el cuestionamiento vinculado a la socialización de las actividades productivas y la pérdida del sentido del emprendimiento, existen variables que determinan la imposibilidad práctica, para el Estado, de intervenir la producción, venta y propiedad del salitre. La primera era la creencia arraigada de que el Estado no podía manejar una operación comercial de envergadura. Bajo la lógica de que no era buen administrador en sus propios negocios, menos podría serlo en los negocios privados, su rol debía centrarse en generar las condiciones necesarias para mantener en operaciones la industria, de modo de dar continuidad a un modelo tributario conveniente.

Una segunda condicionante estaba en la necesidad de contar con capitales propios que permitiesen desarrollar la actividad paralela a la iniciativa privada, o bien para financiar expropiaciones e invertir en mejoras tecnológicas. Tomando en consideración que en 1919 el Estado aún no había cubicado las pampas salitrales, y que tampoco existía una idea certera de la extensión de los terrenos ni menos proyecciones de explotación, que el riesgo fuese asumido por particulares lo eximía de responsabilidades que escapaban a su carácter rentista ${ }^{5}$.

Un último elemento de juicio apunta a un factor tan simple como contundente: no había necesidad alguna de intervenir la industria, menos aún en períodos de crisis. Incluso en años donde el futuro de la industria era incierto, el aporte del salitre a 
las finanzas nacionales era lo suficientemente alto como para no promover cambios sustanciales. En 1918 Alejandro Bertrand señalaba que, considerando los promedios semestrales de las cotizaciones y el costo medio normal, entre 1909 y 1914 el Estado recibió el 65 por ciento de las utilidades totales de la industria. Posiblemente no exageraba. En 1918, un parlamentario recordaba que por cada kilómetro de suelo salitral era necesaria una inversión de entre cuatro y cinco millones de pesos. El Estado, sin invertir, recibía beneficios tres veces mayores que los que podía obtener el industrial, en un período de precios relativamente altos (Bertrand 1918:29; CDSO 27, 8/5/1918:1.717).

El manifiesto rechazo de los industriales a la intervención fiscal también tenía asidero, considerando la rentabilidad del negocio. A inicios de la década de 1910 se estimaba que la inversión de $\$ 50.000$ en una oficina, incluido su capital de exportación, se recuperaba en un plazo de cuatro años. Más reservado en sus estimaciones, un estudio elaborado en 1918 amplió el margen a seis años. En 1914, según estimaba un senador, la utilidad líquida de una salitrera mediana, con capacidad de producción de 300 mil quintales al año, fluctuaba entre el 60 y 75 por ciento del capital invertido $(E l$ Diario Ilustrado [Santiago]: 25/10/1914).

Tratándose, entonces, de un negocio rentable para privados, y de una alternativa óptima de provisión de recursos para el Estado, toda iniciativa tendiente a intervenir la actividad parecía estar condenada a sucumbir ante el peso de la evidencia, y efectivamente así fue.

Como un factor transversal al período estudiado, las propuestas sugeridas, más allá de su insustancialidad teórica y argumentativa, tendieron a conservar el statu quo, esto es, a plantear el rediseño de la estructura de la industria sin alterar significativamente un modelo de intercambio regulado desde el exterior, y cuyos mecanismos de control no se diferenciaron del preexistente durante el ciclo peruano, incluso considerando el período de la estatización. De este modo, el condicionar la participación extranjera o incorporar al Estado en la actividad, como intermediario de la producción o financista, poco o nada variaba el escenario de una industria concentrada en pocas manos y con una influencia en círculos del poder que no se puede desconocer.

Agradecimientos: este artículo es resultado del Proyecto Fondecyt 11090195, del cual el autor es investigador responsable, reuniendo parte de los planteamientos y resultados empíricos de dicha investigación. Agradezco particularmente a los evaluadores sugeridos por la revista. Sus asertivas críticas e indicaciones fueron un real aporte a la discusión del tema propuesto.

\section{Referencias Citadas}

Acción Católica de Chile (compil.) 1932. Las Enseñanzas Sociales de la Iglesia. Rerum Novarum-Quadragesimo Anno, 1891-1931. Imprenta Chile, Santiago.

Acta de la Junta General de la Asociación de Productores de Salitre. 1928. Imprenta Fisher. Valparaíso.

Aldunate, L. 1894. Algunas Rectificaciones Necesarias: Artículos Publicados en El Ferrocarril. Imprenta Excélsior, Valparaíso.

Anexos a la Memoria del Ministerio de Hacienda presentada al Congreso Nacional correspondiente a 1909. 1911. Imprenta Universitaria, Santiago.

Antecedentes sobre la industria salitrera. 1925. Sociedad Imprenta y Litografía Universo, Santiago.

Ávalos, C. 1905. Garantía Fiscal para Establecimientos Destinados al Tratamiento de Minerales de Cobre i Apartado Electrolítico. Imprenta, Litografía i Encuadernación Barcelona, Santiago.

Barone, E. 1931. Principios de Economía Política. Imprenta de la Universidad de Buenos Aires, Buenos Aires.

Bermúdez, O. 1968. El Dr. Nicolás Palacios y la industria del salitre. Revista Chilena de Historia y Geografía 136:199-249.
Bertrand, A. 1912. Conferencias sobre Cuestiones Salitreras dadas en la Universidad de Chile. Imprenta, Litografía y Encuadernación Barcelona, Santiago.

- - - 1910. La Crisis Salitrera: Estudio de las Causas y Caracteres y de las Condiciones Favorables que Caracterizan a la Industria y Comercio del Salitre para Evolucionar en el Sentido de su Concentración Económica. Louis Michaud Editor, Paris.

- - - 1892. Memoria Acerca de la Condición Actual de la Propiedad Salitrera de Chile y Exposición Relativa al Mejor Aprovechamiento de los Salitrales del Estado Presentado al Ministro de Hacienda por el Delegado Fiscal de las Salitreras. Imprenta Nacional, Santiago.

- - - 1918. Política Salitrera. Bases de un Programa de Defensa del Salitre. Imprenta y Litografía Inglesa, Santiago.

Cavarozzi, M. 1978. El orden oligárquico en Chile, 1880-1940. Desarrollo Económico 18(70):231-263.

Certificados salitreros. Informe i liquidación que presenta al señor Ministro de Hacienda el Director del Tesoro. 1887. Imprenta Nacional, Santiago. 
Cleber, F. J. 1923. Nacionalización. Por la Razón o la Fuerza. Imprenta Victoria, Valparaíso.

Convención del Partido Liberal celebrada en Santiago, los días 24, 25 i 26 de diciembre de 1907. 1907. Imprenta, Litografía y Encuadernación Barcelona, Santiago.

Convención del partido Liberal Democrático reunida en Santiago el día 12 de julio de 1908. 1908. Imprenta, Litografía y Encuadernación Barcelona, Santiago.

Couyoumdjian, J.R. 1986. Chile y Gran Bretaña durante la Primera Guerra Mundial y la Postguerra, 1914-1921. Editorial Andrés Bello, Santiago.

Díaz Ossa, B. 1907. El Salitre Sintético. Imprenta, Litografía i Encuadernación Barcelona, Santiago.

Esportación de salitre. Antecedentes del Proyecto de ley que tiende a su incremento. 1915. Imprenta Nacional, Santiago.

Fernández, M. 1981. El enclave salitrero y la economía chilena, 1880-1914. Nueva Historia 3:2-42.

González Aguayo, L. 1969. La nacionalización de bienes extranjeros en América Latina. Ediciones de la Universidad Nacional Autónoma de México. Ciudad de México.

González Miranda, S. 2011. La política salitrera estatal y la política salitrera empresarial: una tensa relación (1880-1910). Actas del Primer Congreso Chileno de Historia Económica: 419-428.

- - - 2012. La resistencia de los tarapaqueños al monopolio salitrero peruano durante el gobierno de Manuel Pardo, desde el estanco a la expropiación (1872-1876). Chungara Revista de Antropología Chilena 44:101-114.

Gellner, E. 1994. Naciones y nacionalismos. Alianza Editorial, Madrid.

González, P. L. 1915. El Carbón Nacional: Medidas para Fomentar su Producción. Empresa Editorial Zig-Zag, Santiago.

Greenhill, R.G. y R.M. Miller 1973. The Peruvian Government and the nitrate trade, 1873-1879. Journal of Latin American Studies 5:107-131.

Hastings, A. 2000. La Construcción de las Nacionalidades. Cambridge University Press, Madrid.

Hobsbawn, E. 2000. Naciones y Nacionalismos desde 1780. Editorial Crítica, Barcelona.

Ibáñez, M. 1893. La Cuestión del Salitre. Imprenta M.J. Mejía, Santiago.

Informe que la Comisión Consultiva de Salitres presenta al señor Ministro de Hacienda. 1880. Imprenta Nacional, Santiago.

Jewkes, J. 1953. The nationalization of industry. The University of Chicago Law Review 20:615-645.

Kirsch, H.W. 1977. Industrial Development in a Traditional Society. The Conflict of entrepreneurship and Modernization in Chile. University of Florida Press, Gainesville.

Konstantin, K. 1963. Teoría de la Nacionalización. Universidad Nacional Autónoma de México, Ciudad de México.
La Convención Conservadora de 1895. Convocatoria, discursos, programa, estatutos, convencionales. 1895. Imprenta y Encuadernación Roma. Santiago.

Lower, M. 1968. Institutional bases of economic stagnation in Chile. Journal of Economic Issues 2:283-297.

Memoria del Delegado Fiscal de Salitreras presentada al señor Ministro de Hacienda en 1903. 1903. Imprenta y Litografía de R. Bini e Hijos. Iquique.

Mena, A. 1916. La Defensa del Salitre. Proyecto de Ley sobre la Organización de la Industria, Comercio y Crédito Salitrero. Imprenta y Encuadernación Fiscal de la Penitenciaría, Santiago.

Millar, R. 1994. Políticas y Teorías Monetarias en Chile. Ediciones de la Universidad Gabriela Mistral, Santiago.

Novoa Monreal, E. 1976. Defensa de las Nacionalizaciones ante Tribunales Extranjeros. Instituto de Investigaciones Jurídicas de la Universidad Nacional Autónoma de México, Ciudad de México.

Olivan, F. 1893. La Combinación Salitrera y sus Hechuras, sus Graves Perjuicios y su Remedio. Imprenta del Universo de Guillermo Helfmann, Valparaíso.

Ortega, L. 2012. La crisis de 1914-1924 y el sector fabril en Chile. Historia 45:433-454.

Ortiz Letelier, F. 2005. El Movimiento Obrero en Chile, 18911919. LOM Editores, Santiago.

Pint, E. 1990. Nationalization and privatization: A rational-choice perspective on efficiency. Journal of Public Policy 10(3):267-298.

Recabarren, L.E. 1915. El Socialismo ¿Qué es el Socialismo? ¿Cómo se Realiza el Socialismo? Imprenta El Despertar, Iquique.

Romero, E. 1949. Historia Económica del Perú. Editorial Sudamericana, Lima.

Sater, W. 1991. Nacionalismo económico y reforma tributaria a fines del siglo XIX en Chile. Estudios de Economía 18(2):215-244.

Subercaseaux, G. 1918. Los Ideales Nacionalistas ante el Doctrinarismo de Nuestros Partidos Políticos Históricos. Imprenta Universitaria, Santiago.

Sundt, F.A. 1907. Proyecto para la Instalación de un Establecimiento de Beneficio de Minerales de Cobre con una Capacidad Anual de Seis mil Toneladas de Cobre fino. Imprenta, Litografía i Encuadernación Barcelona, Santiago.

Sunkel, O. 1982. La Historia Económica de Chile, 1830 y 1930: Dos Ensayos y una Bibliografía. Ediciones Cultura Hispánica del Instituto de Cooperación Iberoamericana, Madrid.

Vergara R., R. 1894. Antecedentes para un Estudio JurídicoEconómico sobre el Salitre. Imprenta Cervantes, Santiago.

Vial, G. 1996. Historia de Chile (1891-1973). Editorial ZigZag, Santiago.

Vicuña, F. [Patriota Viejo] 1880. El Porvenir de la Patria. Imprenta de la Sociedad de Instrucción Primaria, Santiago.

Yunker, J.A. 1997. Economic Justice. The market Socialist Vision. Rowman \& Littlefield Publishers, Boston. 


\section{Notas}

1 Interesantes aproximaciones al tema en Katzarov (1963:3043); Jewkes (1953:615-645); Pint (1990:267-298) y González Aguayo (1969:22-31).

2 El interés del presente artículo descansa en el estudio de la idea de nacionalismo económico, a partir del choque de intereses entre la explotación legítima de recursos naturales con las presiones derivadas del crecimiento del Estado y la redefinición de su institucionalidad. Esto, en el entendido que toda conceptualización teórica sobre el tema, desde fines del siglo XIX, estaba unido a representaciones doctrinarias que sugerían una forzada reforma de las bases económicas de la sociedad. Para el caso chileno, la idea de nacionalizar no se enlaza con el concepto de estatización, ni implica la autoasignación de atribuciones para expropiar bienes o recursos bajo control de privados. Por el contrario, la nacionalización económica sólo buscaba evitar la concentración en manos de extranjeros de bienes considerados estratégicos y, como consecuencia de ello, incrementar los mecanismos de control sobre la actividad productiva desarrollada por particulares. Lo interesante del caso no sólo pasa por que los discursos sobre nacionalización se promueven desde la generación de modelos jurídicos que no invalidan el marco legal precedente, sino que escapan a toda asociación ideológica, al menos en este período. Tratándose de un tema todavía por desarrollar en la historia económica, se sugiere el estudio de Sater (1991:215-244). También Lower (1968:283-297) y Cavarozzi (1978:231-263). Como fuentes del período, sugerentes son los estudios de Bertrand (1918) y Cleber (1923).

3 La historiografía económica nacional ha optado por analizar el impacto del salitre en la economía a partir de variables cuantitativas y econométricas. Desde estas perspectivas, el influjo del mineral en el desarrollo institucional chileno parece ser incuestionable, y se refuerza al comprobar avances en infraestructura pública y una mejora en los estándares de vida de la población. El resultado conlleva, asimismo, la relativización del impacto negativo de los ciclos de contracción en la demanda, y descarta el impacto regional en áreas vinculadas a otros sectores de la producción. Un cuestionamiento a los enfoques tradicionales en las clásicas obras de Kirsch (1977) y Couyoumdjian (1986). Recientemente destaca, con un modelo revisionista del período, el asertivo trabajo de Ortega (2012).

4 En 1892 las compañías anunciaron la formación de la Sociedad Nacional de Explotación del Salitre, la que no se concretó por motivos no precisados.

5 Para las estimaciones del volumen del salitre en Tarapacá y Antofagasta, véase CDSO 27, 13/8/1892:378. 
